The $B D J$ News section accepts items that include general news, latest research and diary events that interest our

readers. Press releases or articles may be edited, and should include a colour photograph if possible. Please direct your correspondence to the News Editor,

Arveen Bajaj at the BDJ, The Macmillan

Building, 4 Crinan Street, London N1 9XW

or by email to bdj@bda.org

\section{Research requires implantologists}

The Association of Dental Implantology have awarded Nilesh Shah from Loughborough and Nigel Rosenbaum from Sheffield a $£ 5,000$ research grant to develop Best Practice guidelines for the consent process in implantology.

The pair are now looking to recruit implantologists who are interested in being involved with this pioneering piece of practice-based research. Participants will need to attend a halfday research training session in the Midlands. Otherwise, disruption to practice will be a minimum.

They will be rewarded with a dedicated study day at the end of the research to help them develop their own world-class consent process, based on the research team's findings.

The research team includes Andrew Toy, Research Champion for East Midlands/South Yorkshire Primary Care Research Network and Dr Reg Dennick, Assistant Director of Medical Education at the University of Nottingham. For more information contact andy. toy@talk21.com with 'Implant Consent Research' in the subject line.

\title{
Oral healthcare themed International meeting
}

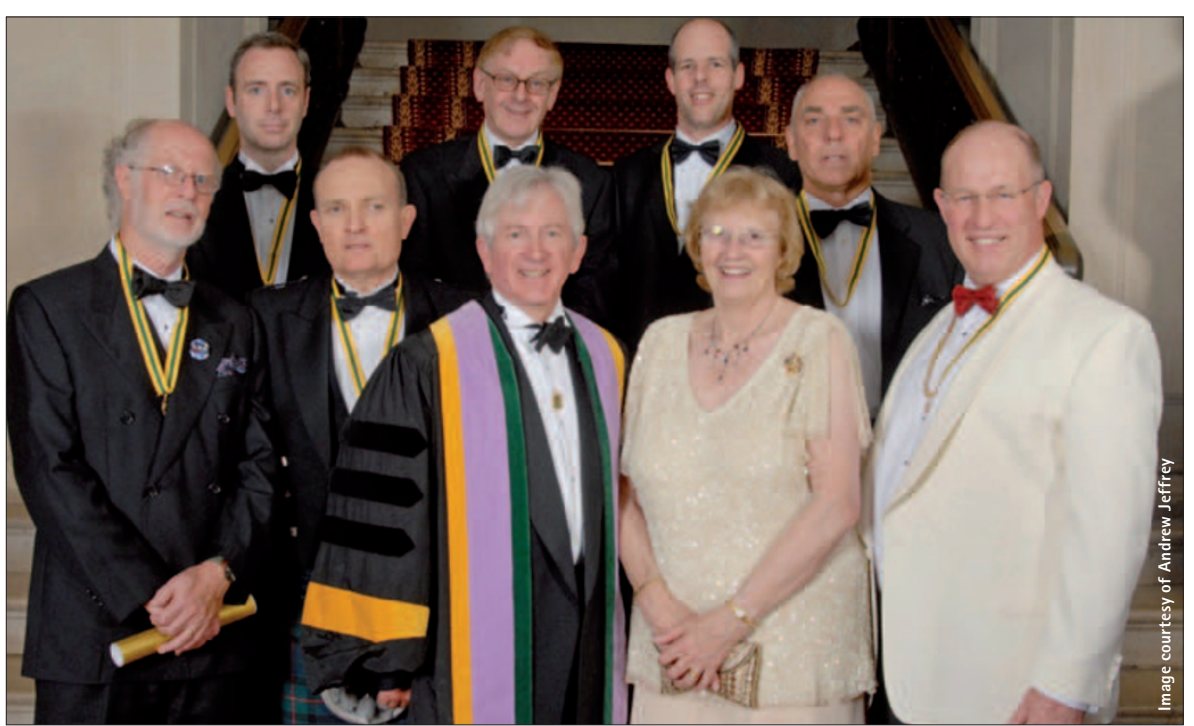

The European section of the International College of Dentists (ICD) held its 52nd Annual meeting in Cardiff recently under the Presidency of Professor Phillip Dowell, Regent for the UK. Over two hundred delegates converged on Cardiff from twenty-one European countries and the USA to attend the three day meeting.

The theme was 'Prospective Eclecticism', a look into various aspects of oral care. The highlight of the final day of the meeting was the induction of 33 new Fellows of the College followed by a gala dinner held at the City Hall and attended by the Rt Honourable Lord Mayor. Pictured above, Dame Margaret Seward who was presented with the award of Master of the ICD, and seven new Fellows, (left to right) Dr Robert Morris, Dr lain Manson, Professor Phillip Dowell, Dame Margaret Seward, Dr Mike Hill, (left to right back row) Dr T Sumner, Professor Hubert Newman, Dr Richard Tucker and Professor Mike Mulcahy. To view all the ICD meeting photos from the final day visit www.photoboxgallery.com/AndrewJeffery and for more information about the College see www.icd-europe.com.

Britain from NHS dentistry, private dentistry and other sources, shows that the proportion derived from NHS work is decreasing.

In 2005-06 less than 42\% of the earnings of GDS non-associates (practitioners holding a general dental services contract who own their surgeries and work in them as the sole dentist) came from the NHS, according to the figures. In $1999-2000$, more than $58 \%$ of dentists' total earnings came from the NHS.
The report also underlines the small gap between the earnings of dentists who earn the majority of their income from NHS or private care.

It shows that GDS non-associates who derived the majority of their income from the NHS received a net income before tax of $£ 96,159$.

Counterparts earning most of their income from private dentistry received a net income before tax of $£ 101,256$. 


\section{Further recognition for dental education}

The Association for Dental Education in Europe has awarded two new chairs in dental education adding to the existing three chairs in the United Kingdom. Patricia Reynolds from King's College

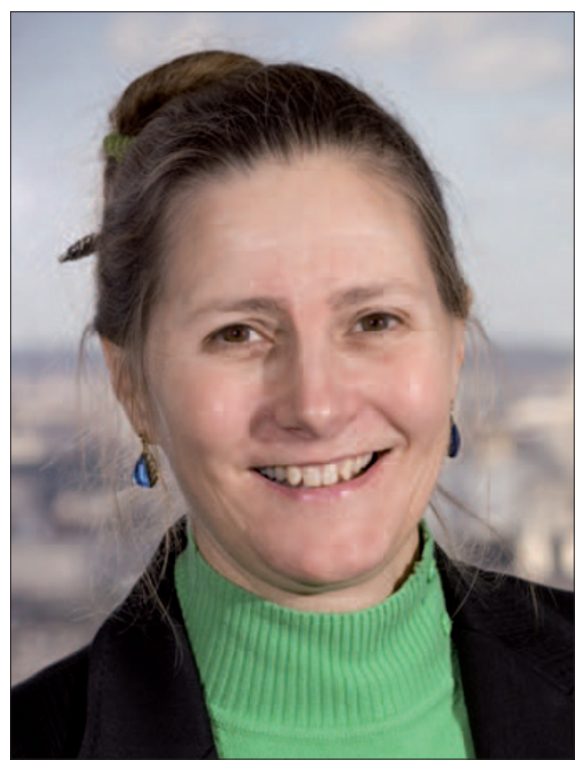

\section{Professionals appointed to hearings panel}

\section{GDO $\begin{aligned} & \text { protecting patients, } \\ & \text { regulating the dental team }\end{aligned}$}

The GDC has announced the appointment of 30 more dental professionals to its independent Fitness to Practise Panel. Members of the panel are responsible for hearing cases where a registered dental professional may not be fit to work because of poor conduct, health or professional performance.

The new appointments will help meet the increasing demand on the panel which now rules on a broader range of hearings, including those about dental professionals' performance and appeals against rejected registration applications. The panel includes lay people as well as dental professionals and now has 78 members in total: 40 dentists, 22 lay people and 16 dental care professionals.
London and Richard Oliver from Cardiff received two out of only five awards by the Association for their outstanding contribution to excellence in dental education. The award recognises their

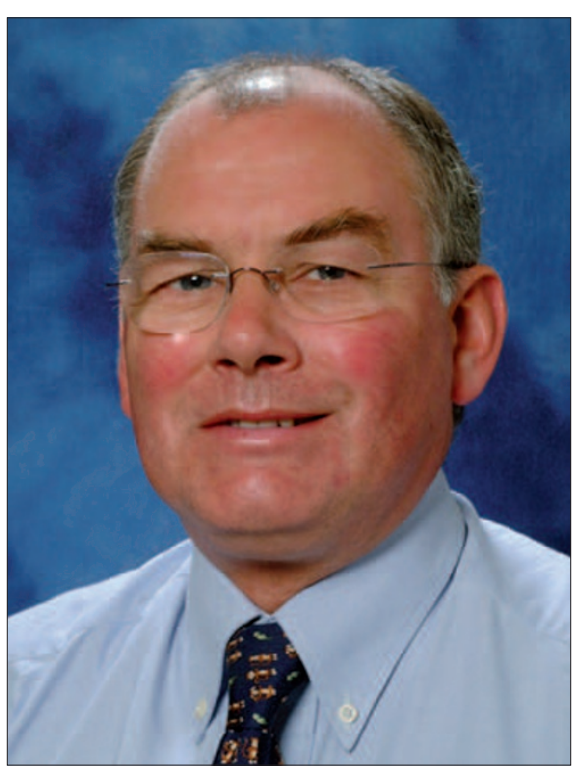

contribution to learning and teaching.

Patricia Reynolds is a specialist in oral surgery and Director of the Centre of Flexible Learning in Dentistry. Her work in education has centred on distance and virtual learning and she is leading the development and promulgation of a HEFCE and Department of Health funded project IVIDENT - International Virtual Dental School, and an ESRC Technology Enhanced Learning project PHANTOM (Personalised Haptics when Teaching with Online Media.)

Richard Oliver is a consultant orthodontist and Director of the Dental Education Unit within the School of Dentistry, Cardiff University. He led the planning and introduction of an extensive revision of the undergraduate curriculum and is now planning the introduction of a dental education degree course specifically designed for teachers within the dental team.

He has special interests in the impact of the Bologna Process on healthcare education in the UK and in portfolios. He has also been heavily involved in DentEd - a thematic network project aimed at bringing convergence of dental education across Europe.

\section{Smoking harms surgery procedures}

A new study has found that smoking damages the long-term stability of certain oral surgical procedures. The research published recently in the Journal of Periodontology (2007; 78:1702-1707) found that smokers had less desirable long-term results following periodontal plastic surgery than non-smokers.

The study followed ten smokers and ten non-smokers for two years to evaluate the effects of cigarette smoke on the long-term outcomes of a treatment to help soft tissue reattach to the root surface of the teeth.

After two years, residual gum recession around the area which received the surgery was greater in smokers as compared to non-smokers. Studies have shown that smoking can impair the body's ability to heal itself immediately after surgery; but this most recent study also showed that when a patient has periodontal plastic surgery, smoking can damage the ability of that procedure to stay intact over a long period of time.

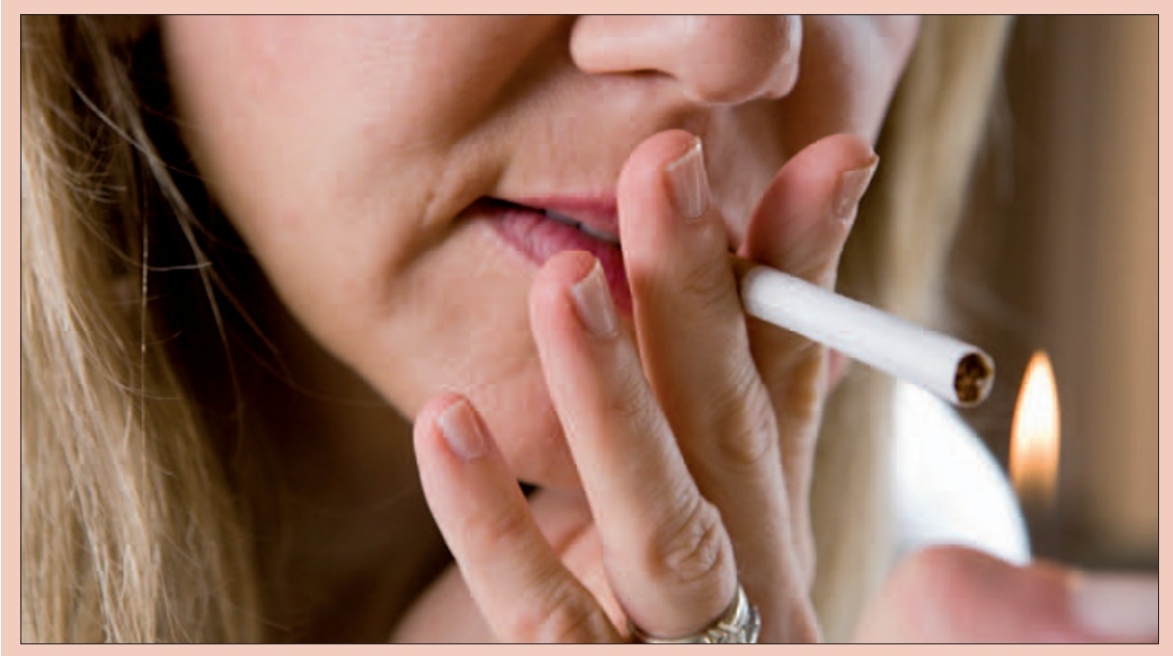




\section{Comprehensive study of mercury in dental fillings begins}

A new study in America is to look at whether prenatal exposure to mercury vapour from fillings affects neurological development. As part of a long-running study of the health effects of low levels of mercury exposure, Associate Professor Gene Watson, from the Eastman Department of Dentistry at the University of Rochester Medical Center (USA) will begin a \$3 million, National Institutes of Health-funded study on prenatal exposure to mercury from dental amalgams or fillings.

Professor Watson will collect hair samples from children in the Indian Ocean island the Seychelles, who were enrolled in a study in 2001 to determine their exposure to methyl mercury from fish and other seafood. He will also record how many fillings the children have and which surfaces of the teeth they cover as an indication of exposure to mercury vapour.

The team chose Seychelles for two main reasons - the fish consumed there have an average level of mercury and mothers eat 12 meals of fish each week. Since 1989, 779 children have been followed and no adverse effects on developmental outcomes were attributed to pre-natal exposure to mercury in seafood. Studies on these and other children in Seychelles are ongoing.

Because these children were enrolled prior to their birth, more information is available than any previous mercury/ dental filling study, Professor Watson claims. 'This study can go back prenatally because we know what the mother's dental history was prior to and during the pregnancy. Little is known about detrimental effects of early exposure, and we need to examine this because studies suggest the developing brain is more susceptible to mercury than the adult brain,' he says.

He adds that while earlier studies on postnatal mercury vapour from dental fillings showed no significant effect on children's neurological function, those studies did not examine whether children may have been exposed through their mother's dental work while still in the womb.

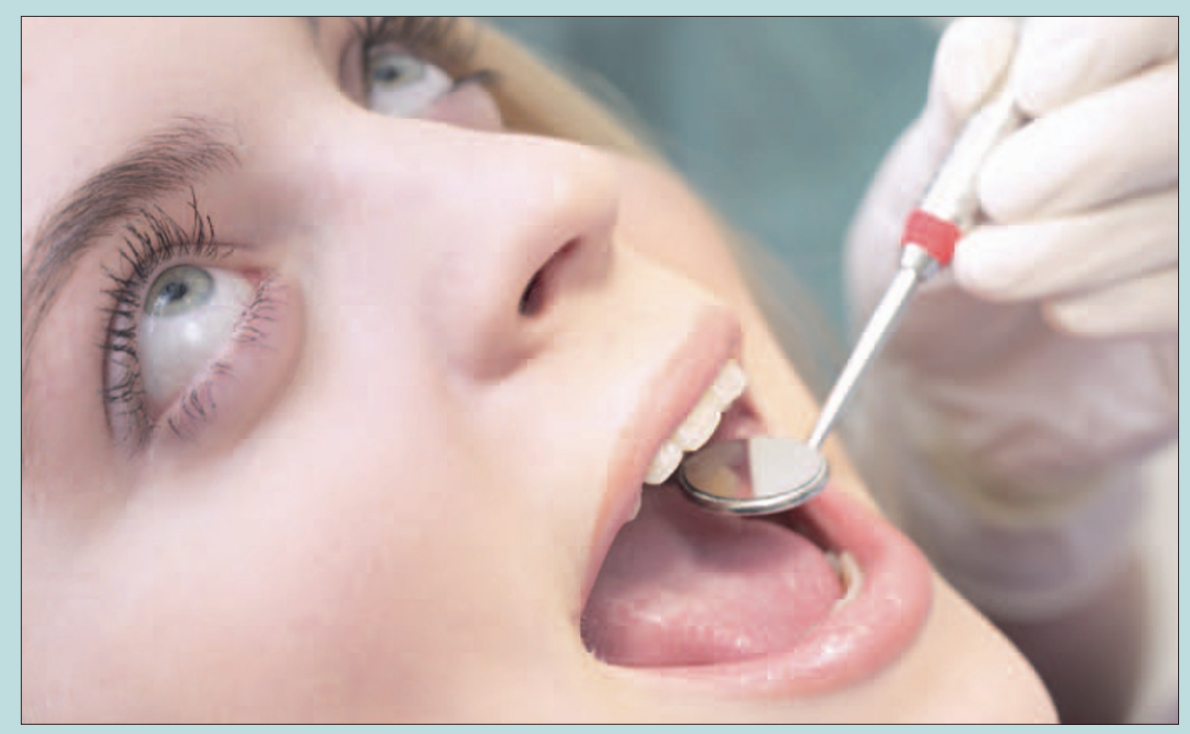

\section{Memorial service}

A memorial service is to be held at Wollaton Road Methodist Church, Beeston, Nottingham on Saturday 13th 0ctober at $2 \mathrm{pm}$ to celebrate the life of Dr Douglas Barber, Dentist of Chortlon-cum-Hardy, Manchester, who died peacefully on 11th August 2007. For more details please contact mhamshere@hotmail.com.

\section{New Masters course launched}

The Kent Centre for Dentistry at the University of Kent and the Faculty of General Dental Practice (UK) have collaborated in the development of a new masters-level programme in primary dental care, due to start in early December 2007.

The training programme can be studied on a part-time basis over one, two or three years.

\section{New awards in mouth cancer awareness}

The Mouth Cancer Foundation is holding its annual Mouth Cancer Awareness Walk on Sunday 14 October 2007 at 1pm in Hyde Park, London. This year, in addition to walk, the Foundation is also organising a new event to raise awareness of the disease, the Mouth Cancer Voice Awards (MCVA). The awards are designed to increase awareness of mouth cancers among university students.

The MCVA will be looking for the newest, most talented, brightest young stars for a talent show of university students that aims to raise their awareness of the risk factors (smoking, drinking and HPV) as well as the symptoms of mouth cancer by making them appreciate their voice, which can be lost through mouth cancer.
University students from across the country will be invited to perform a short demo for one of four categories and upload their demo to the Mouth Cancer Voice Awards 2007 website at www. mouthcancervoice.org. These demos will be turned into video clips that will be voted for by the general public. Three acts in each category will be short listed to attend the grand final at the Vanburgh Theatre, Royal Academy of Dramatic Art (RADA) where they will perform live before a panel of judges and be in with the chance of winning the prize of a lifetime. The final will be held on Sunday 18 November 2007, marking the end of this year's Mouth Cancer Awareness week (11 November to 18 November). For further information on the events visit www.mouthcancerwalk.org. 


\section{New leaflet for reporting concers}

The GDC has launched a new leaflet advising the public on how to report concerns about a dental professional's fitness to practise. The leaflet 'How to report a dental professional to us' explains what patients should do if they are worried that a dental professional is unfit to work because of their skills, health or behaviour; how to report concerns to the GDC; and what will happen as a result.

The leaflet is available to download from the GDC website www.gdc-uk.org. Copies can also be requested from the GDC Communications department on 02070092784 or by email at communications@gdc-uk.org.

\section{Themed meeting}

Special Care Dentistry - from cradle to grave, is the theme of this year's BDA Community Dental Services Group Annual, Presidential and Scientific Meeting from 31 October to 2 November.

\section{Cash injection for NI dentistry}

Northern Ireland Health Minister Michael McGimpsey has announced an injection of $£ 4.4$ million into health service dentistry, addressing the problems of access reported in parts of the province.

The measures announced by the Minister include $£ 1.5$ million being made available to help dentists with the costs of necessary new equipment and procedures, in recognition of the increasing costs of meeting cross-infection control standards. $£ 500,000$ will go towards increasing the vocational training allowances for trainers willing to take on new graduates and help ensure an adequate supply of new young dentists into health service dentistry in Northern Ireland, and up to $£ 400,000$ is being allocated to Boards to address the problem of equity of access to health service dentistry, to enable them to grow the salaried dentists sector to plug gaps in health service provision.

In a statement to the Assembly, the Minister said, 'It has become clear to me that the additional $£ 2$ million funding announced earlier this year, though undoubtedly significant, has not proved sufficient to stop the movement of dentists out of the health service. These new

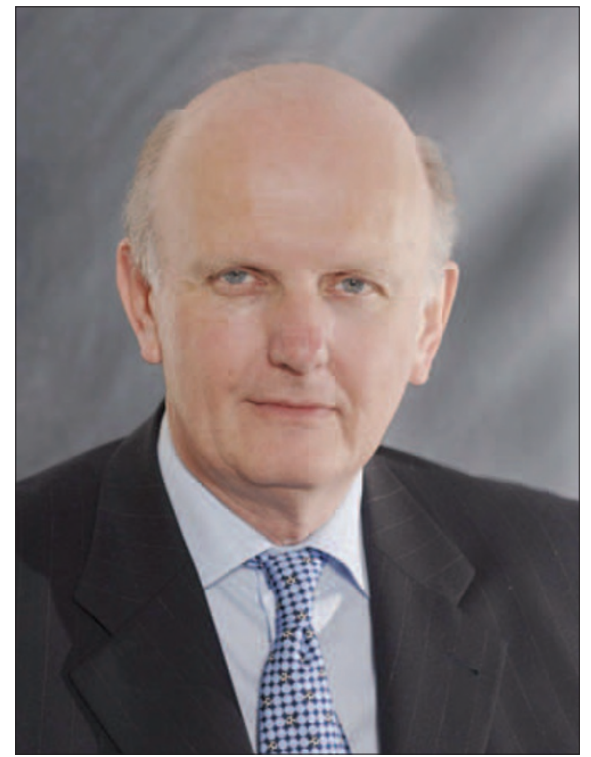

Northern Ireland Health Minister Michael McGimpsey

measures will allow the health service to begin to address directly the problems of gaps in provision which are a matter of real concern to the public.' Northern Ireland has 735 general dental practitioners working out of the 361 registered Health Service practices.

\section{Driving skills investigated}

A preliminary study suggests that patients with cancer in the head and neck region may have inferior performance in some driving skills compared with individuals without the disease, according to a new study.

Researchers from the Medical University of South Carolina, Charleston (USA)

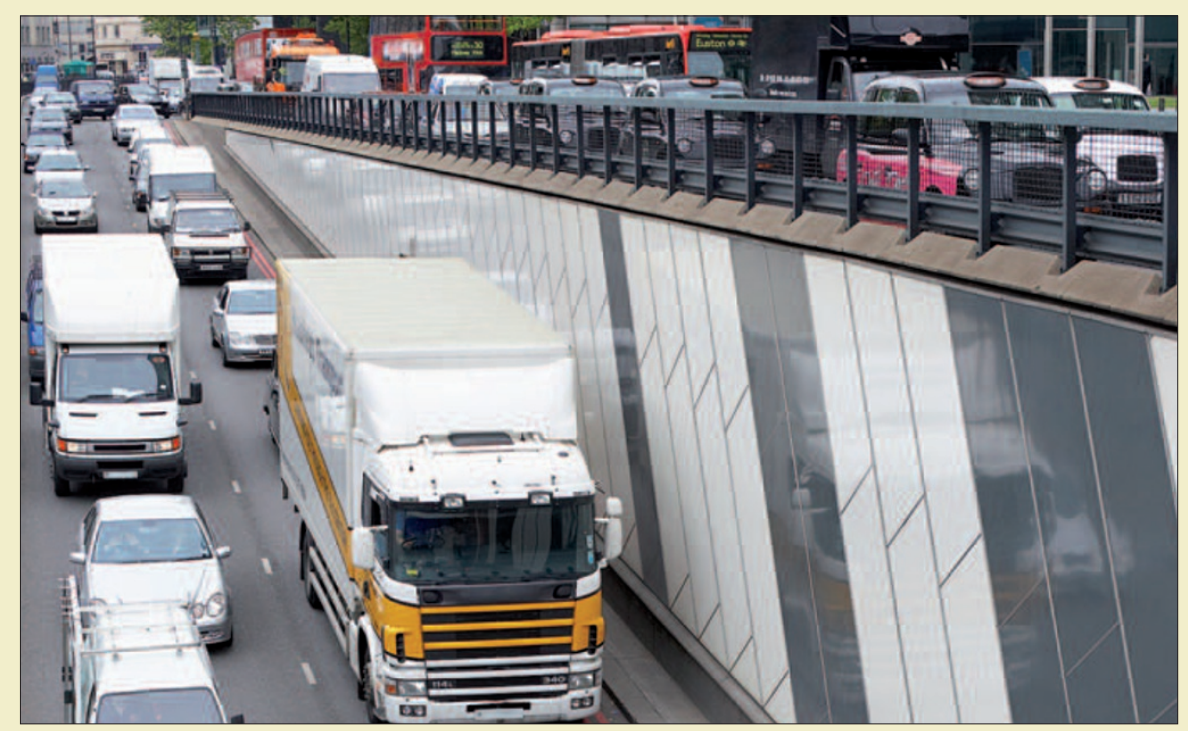

used a virtual reality driving simulator to evaluate the driving skills of ten patients with head and neck cancer with an average age of 56, and 50 members of the community with an average age of 48 .

The team recorded average speed, average brake reaction time, steering variability (vehicle offset from the

centre of driving lane in inches), the total number of collisions and the score of the Simulator Driving Performance Scale, which assesses participants' driving behaviour and skills including braking properly at intersections, driving within the speed limit, using mirrors properly and staying a safe distance from other vehicles.

The average brake reaction time and steering variability in the patients with cancer were significantly longer (3,134.92 milliseconds vs 2,299.8 milliseconds) and larger (271.26 inches $v s$ 46.45 inches), respectively, than those in the control group. There was not a significant difference between the two groups in average speed (21.8 miles per hour $v$ s 25.18 miles per hour), total number of collisions (1.1 vs 1.4) or Simulator Driving Performance Scale scores.

The authors suggested further study was needed to investigate specific causes that may contribute to poor driving performance and the consequences this may have on driving in the real world for patients with cancer. The report was published in the Archives of Otolaryngology-Head \& Neck Surgery, 2007; 133: 904-909. 


\section{DIARY}

October

Safety in clinical practice

Date: 18-19 0ctober, 2007,

Venue: Churchill House, Red Lion Square, London

Email: cmclaughlan@rcoa.ac.uk www.rcoa.ac.uk

BDTA Dental Showcase

Date: 18-20 October 2007

Venue: NEC Birmingham

Tel: 01494789959

www.dentalshowcase.com

North of Scotland BDA Conference and Ceilidh

Date: 20 October 2007

Venue: Apex Hotel and Spa, Dundee

Email: bdascotland@ hotmail.com

Tel: +44 (0)1382635964

Annual meeting of the Society of Craniofacial Genetics \&t American Society of Human Genetics

Date: 23 October 2007

Venue: Convention Center, San Diego,

California, USA

www.craniofacialgenetics.org

FDI Annual World Dental Congress

Date: 24-27 October 2007

Venue: Dubai, UAE

Email:congress@fdiworldental.org

www.fdiworldental.org

November

The Dental Pan-Society Conference 2007 Date: 16-17 November 2007

Venue: International Convention Centre,

Birmingham

Tel: 01494581526

Email admin@pandental2007.org

www.pandental2007.org

Portuguese Dental Association

Annual Meeting

Date: 22-24 November 2007

Venue: Lisbon Conference Centre, Portuga

Email ordem@omd.pt

www.omd.pt

\section{December}

Seventh Annual Premier Symposium Date: Saturday 1 December 2007

Venue: Kings College, London Waterloo campus

Email:sarah.cunliffe@mps.org.uk

www.dentalprotection.org

\section{Confusion over plaque}

Research carried out on behalf of Wrigley Oral Healthcare Programmes earlier this year highlighted confusion over plaque in the UK. It found that $97 \%$ of dental professionals researched believe they talk to their patients about plaque, but less than half of adults in the same survey knew what plaque was.

Equally, although $66 \%$ of dental professionals think their patients know the effects of plaque on their teeth, the research showed that less than 30\% actually understand what plaque is.

The research showed clear differences between the thoughts of hygienists and dentists. Hygienists have been proven to be far more sceptical about their patients understanding whereas the majority of dentists thought their patients to be far more aware about the matter than they actually are.

Wrigley Oral Healthcare Programmes Manager Sas Horscroft said, 'The focus of our programme for 2007 has been to encourage communication between dental professionals and their patients. This is why we have generated the Ask Me About Plaque Campaign to encourage patients to ask their dental professional about plaque. Providing information to dental professionals, both for themselves and their patients, is at the forefront of our campaign and, as a result of the research conducted in May, we have developed a whole host of professional and patient materials on plaque.'

The company operates Oral Healthcare Programmes in 47 countries across the globe, including The Wrigley Orbit Complete Oral Healthcare programme in the UK. The aim of the programme is to help promote better oral healthcare and it is committed to providing patients and professionals with practical resources and materials on oral care in a way that is relevant to today's lifestyle and needs. For more information visit www. BetterOralHealth.info.

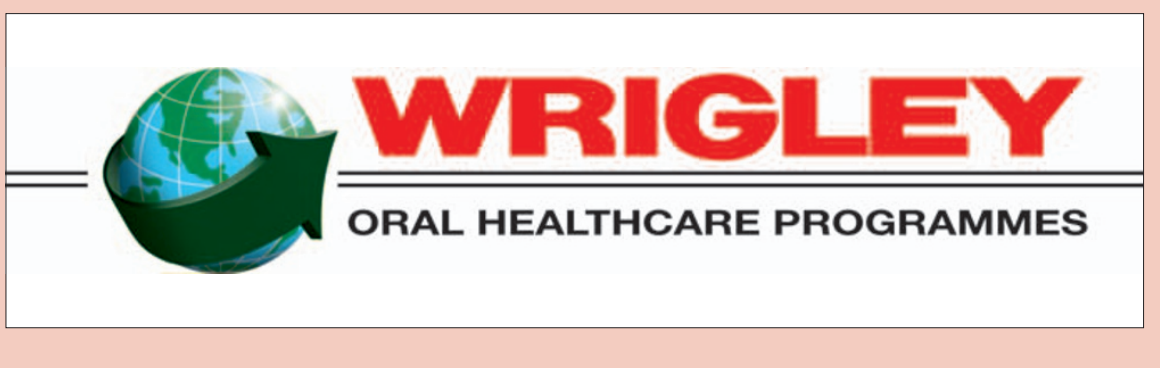

\section{Charity helps victims of radiation and poverty}

In May 2008 Swindon GDP Brendon Ball and his Ukrainian-born wife Natasha will embark on a round-the-world journey by motorcycle which will end at the Annual World Dental Congress in Stockholm. Dr Ball is co-founder of the dental charity Smile Menders which has supplied three surgeries to the Cherkassy region of Ukraine.

The aim of the journey is to raise awareness of the challenges faced by families affected by the combined effects of radiation and poverty. Dr Ball, who has assisted in the dental care of 'Chernobyl Children', states. 'My intention is to visit some dental schools along the way, in particular dentists in Hiroshima and Nagasaki to compare notes on what
I have learned about problems faced by the children and carers of those affected by nuclear fallout.'

The couple will be riding around the world through Canada, Japan and from there to Vladivostok in Siberia before returning to Europe to present a paper at the Stockholm conference.

Before they don their leathers and helmets, Dr Ball and Natasha will be flying out to Ukraine to revisit the Smile Menders' clinics and to present them with a cheque for 10,000 hgrivna $(£ 1,000)$ for restocking the surgeries.

If you can help the charity in any way please contact Brendon Ball at Smile Menders on 01793873044 or email bb @ smilemenders.org. 